Commentary on Sudden Gains and Sudden Losses in the Clients of a "Supershrink": 10 Case Studies

\title{
Rapid Recovery with an Effective Therapist: A Comment on Hansen, Lambert, and Vlass
}

\author{
KEVIN M. LASKA ${ }^{\mathrm{a}, \mathrm{b}}$ \& EDWARD .J. FEDERMAN ${ }^{\mathrm{a}}$ \\ ${ }^{\mathrm{a}}$ Bedford VA Medical Center, Bedford, MA \\ ${ }^{\mathrm{b}}$ Correspondence regarding this article should be addressed to: Kevin M. Laska, 200 Springs Road, Bedford, MA \\ 01730 \\ Email: Kevin.Laska2@va.gov
}

\begin{abstract}
The person of the therapist is a robust predictor of psychotherapy outcome (Wampold \& Imel, 2015). Additionally, some clients make rapid improvements, or sudden gains, in therapy and little is known about the mechanisms underlying this process. In the target article Hansen, Lambert, and Vlass (2015) explore the interaction between these two facets of psychotherapy and discuss how one therapist was able to obtain sudden gains with a high percentage of her clinical caseload. In our comment, we discuss aspects of the therapist who was the focus of the Hansen et al. that we believe contributed to her status as an effective therapist. Furthermore, we discuss the sudden gains obtained by the therapist in Hansen et al., review these improvements within the context of the larger body of evidence and suggest that both case mix as well as therapist skills played a significant role in the exceptional outcomes.
\end{abstract}

Key words: sudden gains; psychotherapy; outcome; case studies; clinical case studies

We appreciate the opportunity to comment on the stimulating article by Hansen, Lambert, and Vlass (2015). The authors provide in-depth case studies of Erigoni Vlass (the third author of their article and hereafter referred to as "Eri"), a highly effective therapist, or "supershrink," and focus on two under examined aspects of the psychotherapy encounter, (a) the person of therapist, and (b) clients who demonstrate rapid recovery or sudden gains. Regarding the former, some have made the claim that "[therapist factors] are not the primary reason why treatments work (if they work)" (Hofmann \& Barlow, 2014, p. 1). This claim is at odds with the most recent metaanalysis that found approximately $5 \%$ of the variability in outcomes is attributable to the therapist (Baldwin \& Imel, 2013). Investigations like the one conducted by Hansen and colleagues improve our knowledge base of potential characteristics of the most effective therapists. Furthermore, little is known about clients who make rapid improvements in therapy. The current article continues the scholarly discussion regarding possible mechanisms of change for clients who obtain sudden gains and what factors impact the overall rate of recovery. The 
importance of these two phenomena and how they interact are critical for improving the quality of mental health services.

We have broken down our comment into two sections. First we discuss the therapist, Eri, and outline what we see as possible contributing factors to her success. We discuss these factors in the context of the psychotherapy process and outcome literature, and how many of the behaviors demonstrated by Eri highlight the importance of addressing the common factors (Wampold \& Imel, 2015) among effective psychotherapy approaches. Second, we discuss the Hansen et al. article in the context of the sudden gains literature and the strengths and limitations of conclusions drawn regarding sudden gains in the current study.

\section{WHAT WE THINK MAKES ERI AN EFFECTIVE THERAPIST}

A growing body of literature has focused on the specific behaviors of highly effective therapists (Ackerman \& Hilsenroth, 2003; Laska \& Nordberg, in press). For example, a recent study found that therapists who achieve better outcomes relative to their peers conduct “deliberate practice," that is, "Individualized training activities especially designed ... to improve specific aspects of an individual's performance through repetition and successive refinement” (Ericsson \& Lehmann, 1996, pp. 278-279). In order to investigate this hypothesis, Chow (2014) examined a sample of 69 therapists and 4,580 clients and found that highly effective therapists spent more time than their peers focusing on ways to improve their practice. In another study by Anderson, Ogles, Patterson, Lambert, and Vermeerch (2009), the authors concluded that highly effective therapists demonstrated a set of behaviors called "facilitative interpersonal skills" (e.g., emotional attunement, persuasiveness), which were predictive of outcome. Although the evidence base is still growing, there is much to learn regarding the specific characteristics of effective therapists. In the current study, Eri demonstrated several behaviors representative of highly effective therapists. Below we discuss specific aspects of Eri's practice that we believe may have contributed to her status as a "supershrink."

\section{Psychoeducation}

A fundamental human trait is the need to make sense of life experience (Chalmers, 1997). When it comes to the experience of human suffering, people have sought out caregivers for this purpose for thousands of years (Harrington, 2008). One of the many functions served by the caregiver is to deliver a credible and culturally embedded explanation for the current state of distress. Although the explanation may look different cross-culturally and across time, all cultures share this as part of the sufferer-healer relationship (Jackson, 1997). Contemporarily speaking, psychotherapy often serves as the setting in which a credible explanation for distress is delivered.

One common factor of many effective psychological treatments is the client receiving an explanation for why they are distressed (Laska, Gurman, \& Wampold, 2014). According to Jerome Frank (1991), people enter psychotherapy because they are "demoralized." That is, they have exhausted their coping mechanisms and may feel hopeless about their ability to change on their own or within their existing social support system. Enter the psychotherapist. One role of 
the therapist here is to provide an answer to the question, "Why do I feel like this?" Different therapists provide this explanation with varying levels of clarity, persuasive power, and believability within the client's conceptual framework. We believe Eri demonstrates a rare ability to deliver a comprehensive and persuasive explanation of the client's presenting problems.

Hansen and colleagues outline six steps that Eri completes in the first session. Eri provides handouts that describe evidenced-based explanations for the client's distress. She gives each client a handout on the neurobiology of stress and the role different areas of the brain play in psychological arousal. We cannot overemphasize the importance of this information. Both of us work in a Veteran's Affairs (VA) hospital and many of the clients we see present with symptoms of post-traumatic stress disorder (PTSD). We have found that Veterans respond positively when they learn the role the amygdala and hippocampus play in their current state of distress. Many are relieved to know that "they are not going crazy;" rather, areas of their brain may not be operating optimally at present, and that treatment can help improve their functioning. It appears that Eri does an extremely thorough and persuasive job explaining to clients why they are experiencing their current level of distress from a neurobiological perspective.

Eri also highlights the importance of extra-theraputic factors as part of the client's healing process. For example, she talks about the role of sleep in improving an individual's ability to regulate emotions. Evidence suggests that sufficient sleep plays a critical role in reducing vulnerability to many psychiatric disorders (Benca, Obermeyer, Thisted, \& Gillin, 1992). She also discusses the role of nutrition and other lifestyle factors in improving overall well-being. Clinical experience suggests that lifestyle factors are often neglected in psychotherapy despite their critically important role in healing and quality of life (Walsh, 2011). Eri manages to cover all these factors in the first session, which likely accelerates the recovery process.

\section{Building A Strong Therapeutic Alliance}

The strength of the therapeutic alliance is one of the most robust predictors of outcome (Horvath, Del Re, Fluckiger, \& Symonds, 2011). One area Eri was particularly strong in was being able to develop meaningful therapeutic relationships with both "Blue" and "Red" cases. Hansen and colleagues hypothesize that Eri's ability to develop a strong therapeutic relationship was one potential reason for her status as an effective therapist and possibly contributed to the sudden gains experienced in the "Blue" cases. We agree. Blue clients rated Eri higher than Red clients on the tasks and goals of therapy. The ability to clearly articulate the expectations for therapy early on in the process, and the specific behaviors the client can perform starting at the first session is, we believe, a strong indicator of an effective therapist. For those who experienced dramatic sudden gains, it appeared Eri was particularly effective at outlining the tasks and goals of therapy from the start, creating positive expectations of change. This is critical for improving outcomes, as noted by Horvath and colleagues (2011)

In the early phases of therapy, modulating the methods of therapy (tasks) to suit the specific client's needs, expectations and capacities is important in building the alliance. The therapist and client need to find the level of collaboration suited to achieve the work of therapy taking into account not only the client's problems, but also the resources, capacities, and 
expectations they bring to therapy. Bridging the client's expectations and personal resources and what the therapist believes to be the most appropriate intervention is an important and delicate task. Alliance emerges, in part, as a result of the smooth coordination of these elements. (p. 15).

The ability of Eri to develop a strong therapeutic alliance and to do so with a broad range of clients more than likely leads to her classification as an effective therapist.

\section{Building a Sense of Mastery}

The next therapist behavior that we believe contributed to Eri's positive outcomes was her ability to help clients build a sense of mastery. Any effective therapist will help improve the client's sense of self-efficacy early in the therapy process. Helping the client to identify strategies to work proactively on their state of mental health is a critical factor in effective treatment. Indeed, many different therapies teach skills early in treatment, which improves the probability of success and increases motivation for change (Swift \& Derthick, 2013). Good therapists will teach various skills early on to capitalize on these factors. Eri incorporated multiple strategies to help clients build a sense of mastery. She approached therapy from an integrative perspective, although her two primary therapeutic influences were cognitive therapy and compassionate mind training (CMT). It was clear that several of Eri's clients, even years later, still recalled the importance of cognitive strategies for helping them reduce their suffering. As noted by one of the Blue clients, Barbara, "She taught me to stop, and think about things. And evaluate what is going on.” Or as stated by the Red client Robert,

One of the things Eri did for me was that she challenged my thinking about what I thought about myself ... she tapped into something and told me: "This is who you are, you need to look at this." It didn't happen straight away. I can look back now; it was good for me to be told that my thinking was distorted $(\mathrm{p}, \quad$ )

Eri quickly helped her clients to critically review their thoughts and how they impact their mood, which likely increased chances for a favorable outcome.

\section{The Use of Feedback}

The final element of Eri's practice we believe contributed to her above average outcomes was the use of a feedback system. There is strong evidence that the use of feedback systems improves psychotherapy outcomes (see Castonguay, Barkham, Lutz, \& McAleavy; Lambert, 2013). Feedback systems provide the therapist and client ongoing information regarding the client's progress during therapy. The benefit of routinely tracking progress throughout therapy is that therapists can respond to therapeutic issues in real time. Furthermore, feedback systems are one way to guard against an overly positive self-assessment bias (Walfish, McAlister, O’Donnell, \& Lambert, 2012), which can negatively impact outcome. Before every session Eri's clients completed the OQ-45 (Lambert, Kahler, Harmon, et al., 2011). Hansen and colleagues do not say much regarding the specifics of how Eri incorporated feedback into therapy, but we presume that her openness to tracking progress and using hard data to guide therapy contributed to her above average outcomes. 
Pragmatic Case Studies in Psychotherapy, http://pcsp.libraries.rutgers.edu

Volume 11, Module 2, Article 2, pp. 202-215, 09-12-15 [copyright by authors]

Having discussed the elements of Eri's practice that we believe contributed to her status and an effective therapist, we now turn our attention to the key phenomenon discussed in Hansen - the topic of sudden gains.

\section{SUDDEN GAINS}

Eri's clients show marked improvement quickly. For example, her 43 clients in the top $10 \%$ of the treatment response had a mean treatment length of 3.9 sessions; and the OQ scores for $93 \%$ of the 85 clients covered in the index study (Hansen, Lambert, \& Vlass, 2015) show statistically significant improvement (see Hansen et al., 2015, Table 2, p. 196). Moreover, the average OQ score for $51 \%$ of the clients decreases from more than one standard deviation above the mean for mental health outpatients ${ }^{1}$ into the normal range, with the same percentage of clients achieving sudden gains. When compared to the treatment response of one national sample (Lambert et al., 2001), this 51\% falls into the top ten percent of treatment responders. These 85 clients are those who completed at least three sessions of psychotherapy, representing just over one-third of the 248 clients seen for at least one session.

To put the index study's results in context, we will review the extent to which sudden gains are a function of case mix and the timing of sudden gains.

\section{Case Mix}

Sudden gains in the treatment of depression are a robust phenomenon that has been documented in various settings with different age groups across psychotherapeutic approaches (Busch, Kanter, Landes, \& Kohlenberg, 2006; Gaynor et al., 2003; Hardy et al., 2005; Hopko, Robertson, \& Carvalho, 2009; Tang \& DeRubeis, 1999) and in clients receiving pharmacotherapy or placebo (Vittengl, Clark, \& Jarrett, 2005) as well as in non-treated samples (Kelly, Roberts, \& Bottonari, 2007). The percentage of clients with sudden gains generally hovers around $40 \%$, with a range from $39 \%$ to $60 \%$ based on the 11 studies of depression included in Aderka's meta-analysis (Aderka, Nickerson, Boe, \& Hofmann, 2012). . Moreover, sudden gains in depression are reliably related to outcome at termination with research finding higher response rates in those who achieved sudden gains than in those who did not, whether a positive response is defined as achieving reliable change (Jacobson \& Truax, 1991) or scores in the non-clinical range. ${ }^{3}$

\footnotetext{
${ }^{1}$ Lambert, Hansen, \& Finch (2001) report that an OQ of 96 is about one standard deviation above the mean for mental health outpatients, which is below the 104.2 average score of $43(51 \%)$ of Eri's clients (see Hansen et al, Table 2, p. ). .

${ }^{2}$ Aderka selected 16 studies for the meta-analysis based on five criteria: original reports of time-limited psychological treatment of sudden gains based on quantitative data collected at every session. He reports each treatment condition in each study separately, which can produce differences in the number of sudden gain clients between conditions that, while apparently large in percentage terms, are not statistically significant (Gaynor et al., 2003). Therefore, we used the percentage of gains for each study in its entirety.

${ }^{3}$ There is some controversy over whether gains are maintained at follow-up for non-CBT interventions (Tang, Luborsky, \& Andrusyna, 2002).
} 
There is limited research investigating the appearance of sudden gains among clients with anxiety disorders or in samples with unrestricted diagnoses; we summarize the five studies included in Aderka's meta-analysis-four studies of clients with anxiety disorders and one sample with unrestricted diagnoses - and one additional large study $(n=1,500)$ of clients with unrestricted diagnoses (Lutz et al., 2013) . The percentage of sudden gains was $19 \%$ for social phobia (Hofmann, Schulz, Meuret, Moscovitch, \& Suvak, 2006), 17\% for a sample with various anxiety disorders (Norton, Klenck, \& Barrera, 2010), 43\% for panic disorder (Clerkin, Teachman, \& Smith-Janik, 2008) ${ }^{4}$ and $16 \%$ for clients with generalized anxiety disorder when all the clients seen at intake were included (Present et al., 2008). However, in this last study, with the sample restricted to those with a Beck Anxiety Inventory (BAI) score of 15 or greater at session one (which excluded more than half the original sample), the percent with sudden gains rose to 35\%. The authors explain restricting the range of scores in this way as being parallel to the restriction other researchers place on their depressed samples, who exclude those with Beck Depression Inventory (BDI) scores below 15 (Tang \& DeRubeis, 1999).

In a general outpatient sample seen in National Health Service clinics in England, 17\% of the clients showed sudden gains (Stiles et al., 2003), while in Lutz's large unrestricted sample, the sudden gain rate was 23\% (Lutz et al., 2013). Although the database is more limited, the sudden gains phenomenon in clients with primary diagnoses of anxiety disorders or in general outpatient samples does not appear as strong as among clients with depression nor are the outcomes of those with anxiety disorders who show sudden gains reliably stronger than those without. $^{5}$

Beutler’s review (Beutler, Blatt, Alimohamed, Levy, \& Angtuaco, 2006) suggests that Axis II disorders compromise psychotherapy outcome in clients with depressive disorders, but this is questioned by other researchers (De Bolle et al., 2011). While none of this work has investigated sudden gains, one may reasonably infer from the close connection between gains and outcome (particularly for depressed clients) that the findings would apply to sudden gains.

In sum, it appears that there are substantial differences in rates of sudden gains depending on the primary diagnosis and that secondary diagnoses may moderate response rates.

\section{Non-Diagnostic Predictors of Symptomatic Response}

Poorer outcomes are predicted by chronic depression vs. single episode or episodic depression (Kelly, Roberts, \& Ciesla, 2005; Köhler et al., 2015) as well as by functional impairment (Beutler et al., 2006; Kelly et al., 2005). Nordberg showed how these general findings applied to the rapid response phenomenon (Nordberg, Castonguay, Fisher, Boswell, \& Kraus, 2014) — a group of high-symptom rapid responders could be distinguished from a group

\footnotetext{
${ }^{4}$ Forty-three clients began this treatment; 13 who completed less than seven sessions were excluded, leaving 30 in the sample analyzed for sudden gains.

${ }^{5}$ Aderka's meta-analysis did not find a difference between the effect sizes for studies of anxiety and depressive disorders. Three points may help explain why our conclusion differs from Aderka's: (a) they included only the restricted sample in the Present study (Present et al., 2008), which dropped more than half the clients enrolled at intake; (2) they analyzed study by condition, while we summarized by study; (3) we included an additional (large) study in our summary.
} 
of high-symptom non-responders. Group membership was predicted by social conflict, suicidality and hostility, while sexual functioning trended toward being a significant predictor. Nordberg makes a key point

previous studies reporting contradictory findings with regard to the relationship between symptom severity and outcome may have included different proportions of the subgroups found herein. Assuming that both groups of treatment responders exist, the relative size of one versus the other would influence the results of any aggregate analysis (p. 12).

This section underscores the importance of ensuring accurate primary and secondary diagnoses and taking into account non-symptomatic factors, including chronicity, when studying sudden gains.

\section{Timing of Sudden Gains}

While the Hansen et al. study provides precise detail regarding the session in which sudden gains appeared, this is often not true for much of the published work on sudden gains. Existing data suggest that the $5^{\text {th }}$ session is often (Hardy et al., 2005; Norton et al., 2010; Stiles et al., 2003; Tang \& DeRubeis, 1999), but far from universally (Lutz et al., 2013), cited as the median for when sudden gains appear. Yet, we know little about the appearance of very early gains, such as those seen in the Blue sample in the index study, particularly those that appear between intake (pre-treatment) and the first session as well as between the first and second sessions. In part, this is because many authors follow Tang and DeRubeis's criteria, including the one that requires having two or three scores prior to the sudden gain to enable a stable pre-post comparison (Tang \& DeRubeis, 1999).

Nevertheless, some authors found Tang and DeRubeis's criterion too restrictive and reported on very early gains. Busch found that $16 \%$ of his sample of persons with depressive disorders showed gains between intake (pre-treatment) and the first session of therapy and another 16\% experienced a gain after the first session (Busch et al., 2006). ${ }^{6}$ Moreover, these very early gains represented nearly $60 \%$ of total symptom improvement across all treatment, and these clients did well at outcome-83\% recovered. In Clerkin's study of panic disorder (Clerkin et al., 2008), 23\% of the sample realized a sudden gain after the first session. Present's (Present et al., 2008) study of panic disorder also provides some clues about responding between intake and the first psychotherapy session. At intake, the mean BAI score of 68 clients was 21.3 (CritsCristoph, Gibbons, Narducci, Schamberger, \& Gallop, 2005). Yet by session one, 37 of those clients scores had dropped below 15 (Present et al., 2008). Neither the original study nor the 2008 Present sudden gains reanalysis gives us the mean scores of the total or restricted sample at session one. Therefore, we are unable to calculate the average drop in scores of the 37 clients whose scores were below a BAI of 15 at session one. Yet the data are suggestive of significant drops for at least a substantial minority of the clients reinforcing the Busch data on significant gains before the first session. In sum, the limited available data suggest that very early gains

\footnotetext{
6 The gains after pre-treatment and session one were equal in absolute and relative size to the criteria followed by Tang and DeRubeis (Tang \& DeRubeis, 1999); Busch did not call them sudden gains since the third criterion (at least two prior sessions) was, by design, not met.
} 
(before the second session) are substantial.

Early sudden gains reliably predict better outcomes than later sudden gains (Bentall, Fisher, Kelly, Bromley, \& Hawksworth, 1989; Kelly et al., 2005; Lutz et al., 2013), emphasizing the need to more closely study very early gains to see if this adds predictive power.

\section{The Blues and the Reds}

Having examined case mix and timing, we turn to a consideration of Eri's ten cases. Table 1 below summarizes five key variables for each of the ten clients as they are described in Hansen et al. In each of the five areas-identifiable single stressor (acute vs. chronic); motivation; resilience/ability to manage emotions; behavioral implementation; and functional impairment—at least four of the five Blues appear better off than all of the Reds. Specifically, four of the five Blues have a single major identifiable stressor, which if/when removed would/did likely lead to rapid improvement or recovery; none of the Reds do. One Blue has a mild level of functional impairment; three reds have chronic high levels; one has intermittent high levels; and one has chronic moderate levels of functional impairment. Similarly, at least four Blues display resilience/ability to manage their emotions and show rapid follow through on behavioral suggestions; none of the Reds show either of these.

In all, it appears that Blues and Reds come from distinct populations. A closer look at the description of the Blues raises questions about diagnoses. One might wonder, for example, whether an adjustment disorder might more aptly describe Beatrice and Brenda, rather than generalized anxiety disorder. Beatrice was responding to a relationship breakup, and Brenda's symptoms cleared when she was told the stressor (bad housing arrangement) would be removed. Another Blue, Barbara, dramatically reduced her alcohol intake following the first session, leading one to wonder about the severity of her diagnosed alcohol abuse disorder, and perhaps raise questions about the diagnosis itself. Finally, Brent (diagnosed with major depressive disorder) and Bailey (diagnosed with generalized anxiety disorder) both reported a primary single source of stress-work - that then impacted them in other ways. Both responded dramatically after a single session, with their scores falling from the clinical to the normal range. Brent's score was 110 (one SD above the clinical mean) to 40 in a single session. This dramatic drop combined with the single identifiable stressor might lead to questions about Brent's diagnosis.

Four of the five Blues had their sudden and very large gains after the first session. We look at the size of the gains in RCI units, which we define as the multiple of the number necessary to show reliable clinical change-14 (Lambert et al., 2004). As Table 2 shows, the sudden gains for the Blues range from 1.7 to 7.1 RCI units, with a mean of 3.8. Looking at the total pre-post change scores for the Blues reveals a range of 4.4 to 6.4 RCI units with a mean of 5.0. To see how this compares to other therapists, we look at a study entitled "Waiting for Supershrink," which reviewed gains made by 1,779 clients seen by 56 therapists (Okiishi, Lambert, Nielsen, \& Ogles, 2003), each of whom saw at least 15 clients. We converted the total OQ-45 change scores from that study into RCI units and report the data for the five therapists that produced the greatest change scores. RCI units of change ranged from 1.25 to 1.48 for the 
pre-post scores, with a mean of 1.35. Eri's pre-post change scores are 3.7 times that of this elite sample of therapists, which are the top $9 \%$ of the 56 therapists in that study. Even Eri's sudden changes scores average 2.8 times that of the entire pre-post change for the top five therapists. This suggests that not only do the Blues in Eri's sample come from a different population than the Reds, but that they come from a different population from those who present to a University Counseling Center in the U.S.

\section{CONCLUSION}

One thing is clear: Eri's Blue clients are getting enormous benefits; they present with a very high level of stress and complete treatment a very short time thereafter, with their symptom levels in the normal range. Hansen, Lamberrt, and Vlass (2015) suggest two possible explanations for this finding: (a) the case mix is easier than in general outpatient mental health settings and (b) Eri is a supershrink. These are not exclusive hypotheses and our review supports both of them. We have tried to demonstrate that the case mix is different from routine outpatient mental health care; notwithstanding that, the data clearly show rapid improvement in clients with high levels of distress in a very brief time.

Hansen and colleagues' thoughtful and thorough presentation of qualitative and quantitative data provides deeper insight into the sudden gains phenomenon. It's a valuable addition to the literature that helps underscore the importance of revising Tang and DeRubeis's third criterion (Tang \& DeRubeis, 1999) and routinely studying very early gains. It addresses persistent questions in the sudden gains literature, including the role of the therapist and the dynamic interplay between client and therapist. Finally, the study adds clinical insight to Nordberg's (Nordberg et al., 2014) separation of high symptomatic rapid responders and high symptomatic non-responders, while underscoring the importance of assessing non-symptomatic factors to inform differential treatment.

\section{REFERENCES}

Ackerman, S. J., \& Hilsenroth, M. J. (2003). A review of therapist characteristics and techniques positively impacting the therapeutic alliance. Clinical Psychology Review, 23, 1-33.

Aderka, I. M., Nickerson, A., Boe, H. J., \& Hofmann, S. G. (2012). Sudden Gains During Psychological Treatments of Anxiety and Depression: A Meta-Analysis Journal of Consulting and Clinical Psychology, 80, 93-101. doi: 10.1037/a0026455

Anderson, T., Ogles, B. M., Patterson, C. L., Lambert, M. J., \& Vermeersch, D. A. (2009). Therapist effects: Facilitative interpersonal skills as a predictor of therapist success. Journal of Clinical Psychology, 65, 755-768. doi:10.1002/jclp.20583

Baldwin, S. A., \& Imel, Z. E. (2013). Therapist effects: Findings and methods. In M. J. Lambert (Ed.), Bergin and Garfield's handbook of psychotherapy and behavior change (6th ed., pp. 258-297). New York, NY: Wiley.

Benca, R. M., Obermeyer, W. H., Thisted, R. A., \& Gillin, J. C. (1992). Sleep and psychiatric disorders: A meta-analysis. Archives of General Psychiatry, 49, 651-658. 
Bentall, R. P., Fisher, D., Kelly, V., Bromley, E., \& Hawksworth, K. (1989). The use of arcade gambling machines: demographic characteristics of users and patterns of use. Br J Addict, 84(5), 555-562.

Beutler, L. E., Blatt, S. J., Alimohamed, S., Levy, K. N., \& Angtuaco, L. (2006). Participant Factors in Treating Dysphoric Disorders In L. G. Castonguay \& L. E. Beutler (Eds.), Principles of therapeutic change that work (pp. 13-63). Oxford: Oxford University Press.

Busch, A. M., Kanter, J. W., Landes, S. J., \& Kohlenberg, R. J. (2006). Sudden gains and outcome: a broader temporal analysis of cognitive therapy for depression. Behavior Therapy, 37, 61-68. doi: 10.1016/j.beth.2005.04.002

Castonguay, L., Barkham, M., Lutz, W., \& McAleavey, A. (2013). Practice-oriented research: Approaches and applications. In M. J. Lambert (Ed.), Bergin and Garfield's handbook of psychotherapy and behavior change (6th ed., pp. 85-133). New York: Wiley.

Chalmers, D. J. (1997). The conscious mind: In search of a fundamental theory. Oxford University Press.

Chow, Daryl. (2014). The study of supershrinks: Development and deliberate practices of highly effective psychotherapists. (unpublished doctoral dissertation). Bentley, Perth, Western Australia: Curtin University, School of Psychology, Faculty of Health Sciences.

Clerkin, E. M., Teachman, B. A., \& Smith-Janik, S. B. (2008). Sudden gains in group cognitivebehavioral therapy for panic disorder. Behavior Research \& Therapy, 46, 1244-1250. doi: 10.1016/j.brat.2008.08.002

Crits-Cristoph, P., Gibbons, M. B. C., Narducci, J., Schamberger, M., \& Gallop, R. (2005). Interpersonal Problems and the Outcome of Interpersonally Oriented Psychodynamic Treatment of GAD. Psychotherapy: Theory, Research, Practice, Training, 42(2), 211224.

De Bolle, M., De Fruyt, F., Quilty, L. C., Rolland, J. P., Decuyper, M., \& Bagby, R. M. (2011). Does personality disorder co-morbidity impact treatment outcome for clients with major depression? A multi-level analysis. Journal of Personality Disorders, 25, 1-15. doi: 10.1521/pedi.2011.25.1.1

Ericsson, K. A., \& Lehmann, A. C. (1996). Expert and exceptional performance: Evidence of Maximal Adaptation to Task Constraints. Annual Review of Psychology, 47(1), 273-305. doi: 10.1146/annurev.psych.47.1.273

Frank, J. D., \& Frank, J. B. (1991). Persuasion and healing: A comparative study of psychotherapy (3rd ed.). Baltimore: Johns Hopkins University Press.

Gaynor, S. T., Weersing, V. R., Kolko, D. J., Birmaher, B., Heo, J., \& Brent, D. A. (2003). The prevalence and impact of large sudden improvements during adolescent therapy for depression: a comparison across cognitive-behavioral, family, and supportive therapy. Journal of Consulting and Clinical Psychology, 71, 386-393.

Hansen, B. P., Lambert, M. J., \& Vlass, E. N. (2015). Sudden gains and losses in the clients of a "supershrink": 10 case studies. Pragmatic Case Studies in Psychotherapy, 11(3), Article 1, 154-201. Available: http://pcsp.libraries.rutgers.edu

Hardy, G. E., Cahill, J., Stiles, W. B., Ispan, C., Macaskill, N., \& Barkham, M. (2005). Sudden gains in cognitive therapy for depression: a replication and extension. Journal of Consulting and Clinical Psychology 73, 59-67. doi: 10.1037/0022-006X.73.1.59

Harrington, A. (2008). The cure within: A history of mind body medicine. New York: 
Random House.

Hofmann, S. G., \& Barlow, D. H. (2014). Evidence-based psychological interventions and common factors approach: The beginnings of a rapproachement? Psychotherapy, 51, 510-513. http://dx.doi.org/10.1037/a0037045

Hofmann, S. G., Schulz, S. M., Meuret, A. E., Moscovitch, D. A., \& Suvak, M. (2006). Sudden gains during therapy of social phobia. Journal of Consulting and Clinical Psychology, 74, 687-697. doi: 10.1037/0022-006X.74.4.687

Hopko, D. R., Robertson, S. M., \& Carvalho, J. P. (2009). Sudden gains in depressed cancer clients treated with behavioral activation therapy. Behaviour Therapy, 40, 346-356. doi: 10.1016/j.beth.2008.09.001

Horvath, A. O., Del Re, A. C., Flückiger, C., \& Symonds, D. (2011). Alliance in individual psychotherapy. Psychotherapy, 48, 9-16.

Jackson, S. W. (1999). Care of the psyche: A history of psychological healing. New Haven: Yale University Press.

Jacobson, N. S., \& Truax, P. (1991). Clinical Significance: A Statistical Approach to Defining Meaningful Change in Psychotherapy Research Journal of Consulting and Clinical Psychology, 59, 12-19.

Kelly, M. A., Roberts, J. E., \& Bottonari, K. A. (2007). Non-treatment-related sudden gains in depression: the role of self-evaluation. Behavioour Research and Therapy, 45, 737-747. doi: 10.1016/j.brat.2006.06.008

Kelly, M. A., Roberts, J. E., \& Ciesla, J. A. (2005). Sudden gains in cognitive behavioral treatment for depression: when do they occur and do they matter? Behav Res Ther, 43(6), 703-714. doi: 10.1016/j.brat.2004.06.002

Köhler, S., Wiethoff, K., Ricken, R., Stamm, T., Baghai, T. C., Fisher, R., . . Adli, M. (2015). Characteristics and differences in treatment outcome of inclients with chronic vs. episodic major depressive disorders. Journal of Affective Disorders, 173, 126-133. doi: 10.1016/j.jad.2014.10.059

Lambert, M. J., Hansen, N. B., \& Finch, A. E. (2001). Client-Focused Research: Using Client Outcome Data to Enhance Treatment Effects Journal of Consulting and Clinical Psychology, 69, 159-172.

Lambert, M. J., Morton, J. J., Hatfield, D., Harmon, C., Hamilton, S., Reid, R. C., et al. (2004). Administration and scoring manual for the Outcome Questionnaire-45. Orem, UT: American Professional Credentialing Services.

Lambert, M. J., Kahler, M., Harmon, C., Shimokowa, K., \& Burlingame, G. (2011). Administration and scoring manual for the Outcome Questionnaire-45.2. Orem, UT: American Professional Credentialing Services.

Lambert, M. J. (2013b). Outcome in psychotherapy: The past and important advances. Psychotherapy, 50, 42-51. doi:10.1037/a0030682

Laska, K. M., Gurman, A. S., \& Wampold, B. E. (2014). Expanding the lens of evidencebased practice in psychotherapy: A common factors perspective. Psychotherapy, 51, 467-481. http://dx.doi.org/10.1037/ a0034332

Laska, K. M., \& Nordberg, S. S. (in press). Therapist characteristics and strategies for enhancing the therapeutic alliance and treatment outcomes with adults. In The Oxford Handbook of Treatment Processes and Outcomes in Counseling Psychology. 
Lutz, W., Ehrlich, T., Rubel, J., Hallwachs, N., Röttger, M. A., Jorasz, C., . . . Tschitsaz-Stucki, A. (2013). The ups and downs of psychotherapy: sudden gains and sudden losses identified with session reports. Psychotherapy Research, 23, 14-24. doi: 10.1080/10503307.2012.693837

Nordberg, S. S., Castonguay, L. G., Fisher, A. J., Boswell, J. F., \& Kraus, D. (2014). Validating the rapid responder construct within a practice research network. Journal of Clinical Psychology, 70, 886-903. doi: 10.1002/jclp.22077

Norton, P. J., Klenck, S. C., \& Barrera, T. L. (2010). Sudden gains during cognitive-behavioral group therapy for anxiety disorders. Journal of Anxiety Disorders, 24, 887-892. doi: 10.1016/j.janxdis.2010.06.012

Okiishi, J., Lambert, M. J., Nielsen, S. L., \& Ogles, B. M. (2003). Waiting for Supershrink: An Empirical Analysis of Therapist Effects Clinical Psychology and Psychotherapy, 10, 361373.

Present, J., Crits-Cristph, P., Gibbons, M. B. C., Hearon, B., Ring-Kurtz, S., Worley, M., \& Gallop, R. (2008). Sudden Gains in the Treatment of Generalized Anxiety Disorder. Journal of Clinical Psychology, 64(1), 119-126

Stiles, W. B., Leach, C., Barkham, M., Lucock, M., Iveson, S., Shapiro, D. A., .. . Hardy, G. E. (2003). Early sudden gains in psychotherapy under routine clinic conditions: practicebased evidence. Journal of Consulting and Clinical Psychology, 71, 14-21.

Swift, J. K., \& Derthick, A. O. (2013). Increasing hope by addressing clients outcome expectations. Psychotherapy Research, 50, 284-287.

Tang, T. Z., \& DeRubeis, R. J. (1999). Sudden gains and critical sessions in cognitive-behavioral therapy for depression. Journal of Consulting and Clinical Psychology, 67, 894-904.

Tang, T. Z., Luborsky, L., \& Andrusyna, T. (2002). Sudden gains in recovering from depression: are they also found in psychotherapies other than cognitive-behavioral therapy? Journal of Consulting and Clinical Psychology, 70, 444-447.

Vittengl, J. R., Clark, L. A., \& Jarrett, R. B. (2005). Validity of sudden gains in acute phase treatment of depression. Journal of Consulting and Clinical Psychology, 73, 173-182. doi: 10.1037/0022-006X.73.1.173

Walfish, S., McAlister, B., O'Donnell, P., \& Lambert, M. J. (2012). An investigation of selfassessment bias in mental health providers. Psychological Reports, 110(2), 639-644. doi: http://dx.doi.org/10.2466/02.07.17.PR0.110.2.639-644

Walsh, R. (2011). Lifestyle and mental health. American Psychologist, 66, 579-592.

Wampold, B. E., \& Imel, Z. E. (2015). The great psychotherapy debate: The research evidence for what works in psychotherapy (2nd ed.). New York, NY: Routledge. 
Pragmatic Case Studies in Psychotherapy, http://pcsp.libraries.rutgers.edu

Volume 11, Module 2, Article 2, pp. 202-215, 09-12-15 [copyright by authors]

Table 1. Non-Symptomatic Variables

\begin{tabular}{|c|c|c|c|c|c|c|}
\hline & $\begin{array}{c}\text { Identifiable } \\
\text { single major } \\
\text { external } \\
\text { stressor/ } \\
\text { Acute vs. } \\
\text { Chronic } \\
\end{array}$ & Motivation & $\begin{array}{c}\text { Resilience/Ability } \\
\text { to manage } \\
\text { emotions }\end{array}$ & $\begin{array}{c}\text { Behavioral } \\
\text { implementation }\end{array}$ & $\begin{array}{l}\text { Functional } \\
\text { Impairment }\end{array}$ & Notes \\
\hline \multicolumn{7}{|c|}{ BLUES } \\
\hline Brent & Yes & High & Yes & Rapid & No & Work stress \\
\hline Bailey & Yes & na & Yes & Rapid & No & Work stress \\
\hline Barbara & $?$ & High & $?$ & Rapid & Mild & $\begin{array}{l}\text { Unable to } \\
\text { study }\end{array}$ \\
\hline Beatrice & Yes & High & Yes & na & No & \begin{tabular}{|c}
$\begin{array}{c}\text { Relationship } \\
\text { breakup }\end{array}$ \\
\end{tabular} \\
\hline Brenda & Yes & High & Yes & Yes & No & Bad housing \\
\hline \multicolumn{7}{|c|}{ REDS } \\
\hline Robert & Chronic & Yes & No & No & $\begin{array}{c}\text { High } \\
\text { intermittent }\end{array}$ & $\begin{array}{c}\text { Etoh \& drug } \\
\text { abuse; } \\
\text { memory } \\
\text { problems } \\
\end{array}$ \\
\hline Rachelle & Chronic & No & No & No & High & $\begin{array}{l}\text { Physical } \\
\text { abuse }\end{array}$ \\
\hline Rebecca & Chronic & No & na & No & Moderate & $\begin{array}{c}\text { Prolonged } \\
\text { complicated } \\
\text { grief reaction }\end{array}$ \\
\hline Reilly & Mixed & na & No & No & High & $\begin{array}{c}\text { Accident, } \\
\text { also } \\
\text { longstanding } \\
\text { interpersonal } \\
\text { problems } \\
\end{array}$ \\
\hline Ruby & Chronic & No & No & na & High & $\begin{array}{c}\text { “... she } \\
\text { would } \\
\text { require long- } \\
\text { term } \\
\text { treatment } \\
\text { develop a } \\
\text { stable sense } \\
\text { of identity” }\end{array}$ \\
\hline
\end{tabular}


K.M. Laska \& E.J. Federman

Pragmatic Case Studies in Psychotherapy, http://pcsp.libraries.rutgers.edu

Volume 11, Module 2, Article 2, pp. 202-215, 09-12-15 [copyright by authors]

Table 2. Initial and Possible Diagnoses; RCI Units at Sudden Gain/Loss and Pre-Post Change

\begin{tabular}{|c|c|c|c|c|c|}
\hline Client & $\begin{array}{l}\text { Initial } \\
\text { diagnosis }\end{array}$ & $\begin{array}{l}\text { Sudden gain } \\
\text { Change (RCI } \\
\text { units) }\end{array}$ & $\begin{array}{l}\text { Pre-post change/ } \\
\text { RCI units }\end{array}$ & Possible Dx & Notes \\
\hline \multicolumn{6}{|c|}{ BLUES } \\
\hline Brent & MDD* & -5.0 & -6.4 & $\begin{array}{c}\begin{array}{c}\text { Adjustment } \\
\text { disorder }\end{array} \\
\end{array}$ & \\
\hline Bailey & GAD* & -2.9 & -2.8 & $\begin{array}{c}\begin{array}{c}\text { Adjustment } \\
\text { disorder }\end{array} \\
\end{array}$ & \\
\hline Barbara & $\begin{array}{c}\text { MDD, Alcohol } \\
\text { Abuse } \\
\text { Disorder }\end{array}$ & -2.1 & -5.9 & $\begin{array}{l}\text { Question alcohol } \\
\text { abuse diagnosis }\end{array}$ & $\begin{array}{l}\text { Dramatically } \\
\text { reduced ETOH } \\
\text { after 1st session }\end{array}$ \\
\hline Beatrice & GAD & -1.7 & -4.4 & $\begin{array}{c}\begin{array}{c}\text { Adjustment } \\
\text { disorder }\end{array} \\
\end{array}$ & \\
\hline Brenda & GAD & -7.1 & -5.5 & $\begin{array}{l}\text { Adjustment } \\
\text { disorder; }\end{array}$ & \begin{tabular}{|c|} 
OQ scores \\
dropped \\
dramatically after \\
being told of move \\
to another housing \\
unit \\
\end{tabular} \\
\hline \multicolumn{6}{|c|}{ REDS } \\
\hline Robert & Bipolar I & 1.4 & -2.3 & & $\begin{array}{c}\text { Hx of etoh and } \\
\text { drug abuse; } \\
\text { memory problems }\end{array}$ \\
\hline Rachelle & MDD & 3.4 & -2.1 & \begin{tabular}{|c|} 
Borderline \\
Personality \\
Disorder \\
characteristics; \\
physically abused \\
\end{tabular} & \\
\hline Rebecca & MDD & 0.1 & 1.0 & & \\
\hline Reilly & $\begin{array}{l}\text { GAD, Pain } \\
\text { Disorder }\end{array}$ & 1.1 & 1.9 & & \\
\hline Ruby & MDD & 2.8 & -1.5 & $\begin{array}{c}\text { "Histrionic } \\
\text { personality style" }\end{array}$ & $\begin{array}{l}\text { “... she would } \\
\text { require long-term } \\
\text { treatment ... to } \\
\text { develop a stable } \\
\text { sense of identity” }\end{array}$ \\
\hline
\end{tabular}

